\title{
REVIEW
}

\section{Pre-exposure Prophylaxis for HIV Prevention: Why, What, Who and How}

Olubanke Davies · Andrew Ustianowski · Julie Fox (D)

Received: June 29, 2016 / Published online: September 27, 2016

(c) The Author(s) 2016. This article is published with open access at Springerlink.com

\section{ABSTRACT}

Pre-exposure prophylaxis (PrEP) offers a promising new approach to HIV prevention. It is protective against HIV infection across populations and has few significant safety risks and little evidence of behavioural risk compensation. This article summarises the evidence behind HIV PrEP as an intervention, populations that may benefit, current guidelines and programmes, and the cost-effectiveness modelling of this strategy.

Keywords: HIV; PrEP; Review

Enhanced content To view enhanced content for this article go to http://www.medengine.com/Redeem/ 5395F0606A37D413.

O. Davies · J. Fox (四)

Department of Genitourinary Medicine, Guys and St Thomas' NHS Trust, London, UK

e-mail: julie.fox@kcl.ac.uk

A. Ustianowski

Infectious Diseases, North Manchester General

Hospital, Manchester, UK

\section{INTRODUCTION}

Despite significant advances in treatment, HIV infection remains a very significant burden on individuals, communities, healthcare systems and economies around the world. HIV incidence rates remain stable and costs unsustainable, making HIV a public health priority. The use of pre-exposure prophylaxis (PrEP) in HIV-negative individuals who are at high risk of HIV acquisition is an emerging strategy to add to the toolbox of HIV prevention. This article summarises the evidence behind HIV PrEP as an intervention, populations that may benefit, current guidelines and programmes, and the cost-effectiveness modelling of this strategy.

\section{Compliance with Ethics Guidelines}

This article is based on previously conducted studies and does not involve any new studies of human or animal subjects performed by any of the authors. 


\section{EVIDENCE FOR PREP}

\section{Tenofovir Disoproxil Fumarate-Based PrEP}

Ten randomised controlled trials have investigated the use of PrEP utilising tenofovir, five providing evidence for the effectiveness of daily oral tenofovir disoproxil fumarate $[1,2]$ or Truvada (tenofovir disoproxil fumarate/ emtricitabine fixed dose combination tablet) [3-5], one for event-driven Truvada taken before and after sex [6], two for event-driven topical tenofovir gel $[7,8]$ and two for daily tenofovir vaginal gel $[9,10]$.

Effectiveness for oral tenofovir-based regimens has been demonstrated in men who have sex with men (MSM) [3, 4, 6], heterosexual serodiscordant couples [1], young heterosexual adults (male and female) [5]) and injecting drug users [2]. Tenofovir 1\% vaginal gel applied before and after sex resulted in a modest reduction in HIV incidence in women in Kwazulu-Natal [7] but no reduction in a further trial conducted in South Africa [8]. Two randomised placebo-controlled trials conducted in women in Sub-Saharan Africa observed no benefit for daily oral tenofovir or Truvada or daily tenofovir $1 \%$ vaginal gel $[9,10]$; these studies however experienced low levels of retention and adherence, and biological efficacy is supported by subset analyses in women using gel who had detectable drug in plasma (and demonstrated protection) $[8,10]$.

\section{Main Tenofovir PrEP Studies}

The iPrEx study was a double-blind, placebo-controlled study of daily Truvada-based PrEP in men and male-to-female transgender adults who reported sex with men in the 6 months prior to enrolment in 6 countries. An overall $44 \%$ risk reduction was seen, which increased to $73 \%$ where self-reported adherence was $>90 \%$ and to $92 \%$ in those with detectable plasma drug levels [4]. In the open-label extension of the iPrEx study (iPrEx OLE), 100\% efficacy was reached in those taking four or more doses a week [11].

More recently two randomised trials using Truvada in European MSM populations were reported. PROUD was an open-label design (daily Truvada versus no drug) [3] and IPERGAY a placebo-controlled design evaluating event-based Truvada (two tablets before sex and one a day for 2 days after the last condomless anal sex act) [6]. In both trials the HIV incidence in the control group was much higher than anticipated, 9.0/100 person years in PROUD and 6.6/100 person years in IPERGAY. Indeed the incidence in PROUD was seven fold higher than in MSM attending sexual health clinics. The reductions in HIV acquisition in both trials (by ITT analysis) were $86 \%$, which is the highest efficacy observed in PrEP trials to date. Interestingly, IPERGAY achieved this using half the number of doses compared to daily dosing of the drug. Concern that PrEP would reduce condom use when knowingly taking PrEP was assessed in the open-label PROUD study whereby patients knew whether they were taking effective PrEP or not and no difference was found in sexually transmitted infections between the groups [3].

One study (from Thailand) has explored tenofovir-based PrEP in preventing HIV transmission via intravenous drug use and found an almost 50\% risk reduction in HIV acquisition [2].

\section{Non-Tenofovir-based PrEP}

Tenofovir-based PrEP is not without potential toxicities with reduction in bone mineral 
density [12, 13] and renal function [14] observed albeit in low numbers. As a result other PrEP agents are being investigated: tenofovir alafenamide (TAF) is a pro-drug of tenofovir with theoretical advantages in terms of decreased renal and bone adverse events and decreased monitoring requirements. However, although macaque data appear promising [15], there are presently no efficacy data in humans and vaginal drug levels appear to be lower than those achieved with tenofovir disoproxil [16]. Whether 3TC could be used instead of FTC in PrEP has not been evaluated in a clinical trial; however, a systematic review and meta-analysis of randomised trials concluded that there would be comparative efficacy of lamivudine and emtricitabine for PrEP efficacy $(p=0.88)$ [17] (Table 1).

Maraviroc has not shown protection from HIV in ex-vivo challenge models, whether via stat dosing across rectal and vaginal mucosa or daily dosing across rectal mucosa [18, 19]. Taken orally in combination with other antiretroviral agents, Maraviroc is well tolerated but PrEP efficacy is not known $[20,21]$. Cabotegravir (as 2-monthly injections) also shows promise [22] and a phase 3 efficacy study is underway. Two randomised control trials of the dapivirine intravaginal ring reported consistent results. Although the ITT benefit was small, post hoc analyses excluding younger women (less than 25 years of age) who were less likely to have detectable drug revealed modest protection benefits [61\% (32-77) risk reduction] [23].

\section{PROS AND CONS OF DAILY AND EVENT-DRIVEN ORAL PREP}

The two current main models of oral PrEP are daily dosing (tenofovir disoproxil fumarate or Truvada) (as in iPrEX and PROUD) or event-driven usage (as in IPERGAY). Both strategies have demonstrated utility in trials, but their applicability may differ between populations and settings.

\section{Daily PrEP}

Daily tenofovir-based PrEP has shown good efficacy in a variety of populations, but requires good adherence and frequent repeat HIV testing to minimise the associated antiretroviral resistance that can occur as a consequence of PrEP failure [24]. It can also lead to drug wastage if taken during periods of low sexual risk and potentially cause toxicity (principally bone and renal) if taken long term [25]. Renal and bone monitoring may be unavailable or operationally difficult and costly (especially in resource-poor/remote settings), and toxicities may differentially affect specific populations. For example, bone loss (which is pronounced in adolescents) is of particular concern in countries such as Botswana where up to $7 \%$ of healthy young adults have low bone mineral density [12].

\section{Event-Driven PrEP}

Event-driven PrEP has only been investigated in MSM populations (and therefore efficacy is unproven with heterosexual or needle-based transmission). If efficacy is substantiated in future studies, this strategy has the potential to improve cost effectiveness, whilst reducing drug wastage, reduce toxicity and monitoring requirements-as there will be natural interruptions during periods of no risk. Furthermore, in contrast to daily PrEP, event-driven PrEP has not (to date) led to any cases of drug-resistant HIV. However this may change as implementation is rolled out. Transmitted tenofovir resistance is already a 
Table 1 Key studies examining efficacy of Tenofovir-based PrEP

\begin{tabular}{|c|c|c|c|}
\hline $\begin{array}{l}\text { Route of } \\
\text { exposure }\end{array}$ & Interventions & Evidence & $\begin{array}{l}\text { Positive benefit } \\
\text { demonstrated? }\end{array}$ \\
\hline \multirow{6}{*}{$\begin{array}{l}\text { Homosexual } \\
\text { men/MSM }\end{array}$} & \multirow{6}{*}{$\begin{array}{l}\text { Truvada (Tenofovir } \\
\text { disoproxil fumarate \& } \\
\text { Emtricitabine) }\end{array}$} & $N=2499$ & \multirow[t]{2}{*}{$\mathrm{Y}$} \\
\hline & & $\begin{array}{l}44 \% \text { reduction in the incidence of HIV ( } 95 \% \text { confidence } \\
\text { interval }[\mathrm{CI}] 15-63 ; p=0.005)[4]\end{array}$ & \\
\hline & & $N=275$ (in immediate PrEP group) & \multirow[t]{2}{*}{$\mathrm{Y}$} \\
\hline & & $\begin{array}{l}\text { Relative reduction } 86 \%(90 \% \text { CI } 64-96, p=0 \cdot 0001 \text {; } \\
\text { absolute difference } 7 \cdot 8 / 100 \text { person-years, } 90 \% \mathrm{CI} \\
4 \cdot 3-11 \cdot 3)[3]\end{array}$ & \\
\hline & & $N=414$ & \multirow[t]{2}{*}{ Y } \\
\hline & & Relative reduction of $86 \%$ (95\% CI $40-98 ; p=0.002$ ) [6] & \\
\hline \multirow{2}{*}{$\begin{array}{l}\text { Injecting drug } \\
\text { users }\end{array}$} & \multirow{2}{*}{$\begin{array}{l}\text { Tenofovir disoproxil } \\
\text { fumarate }\end{array}$} & $N=1204$ & \multirow[t]{2}{*}{ Y } \\
\hline & & $\begin{array}{l}\text { Reduction of } 48.9 \% \text { in incidence }(95 \% \text { CI } 9 \cdot 6-72 \cdot 2 \text {; } \\
p=0 \cdot 01)[2]\end{array}$ & \\
\hline \multirow{6}{*}{$\begin{array}{l}\text { Heterosexual } \\
\text { men and } \\
\text { women }\end{array}$} & \multirow[t]{2}{*}{ Tenofovir disproxil fumarate } & $N=1584$ & \multirow[t]{2}{*}{ Y } \\
\hline & & $\begin{array}{l}\text { Relative reduction of } 67 \% \text { in incidence of HIV-1 }(95 \% \mathrm{CI} \\
44-81 ; p<0.001)[1]\end{array}$ & \\
\hline & \multirow{4}{*}{$\begin{array}{l}\text { Truvada (Tenofovir } \\
\text { disoproxil fumarate \& } \\
\text { Emtricitabine) }\end{array}$} & $N=1579$ & \multirow[t]{2}{*}{$\mathrm{Y}$} \\
\hline & & $\begin{array}{l}\text { Relative reduction of } 75 \% \text { in incidence of HIV-1 (95\% CI } \\
55-87 ; p<0.001) \text { [1] }\end{array}$ & \\
\hline & & $N=611$ & \multirow[t]{2}{*}{$\mathrm{Y}$} \\
\hline & & Efficacy $62.2 \%(95 \%$ CI $21.5-83.4 ; p=0.03)[5]$ & \\
\hline \multirow[t]{11}{*}{ Women } & \multirow[t]{7}{*}{ 1\% Tenofovir Vaginal Gel } & $N=445$ & \multirow[t]{3}{*}{ Y } \\
\hline & & Estimated reduction of $39 \%$ overall & \\
\hline & & (54\% in women with high gel adherence) [7] & \\
\hline & & $N=2059$ total (gel or placebo) & \multirow[t]{2}{*}{$\mathrm{N}$} \\
\hline & & Incidence rate ratio $1.0(95 \% \mathrm{CI} 0.7-1.4)[8]$ & \\
\hline & & $N=996$ & \multirow[t]{2}{*}{$\mathrm{N}$} \\
\hline & & Hazard ratio 0.85 (95\% CI 0.61-1.21) [10] & \\
\hline & $\begin{array}{l}\text { Tenofovir disoproxil } \\
\text { fumarate }\end{array}$ & $\begin{array}{l}N=993 \\
\text { Hazard ratio } 1.49(95 \% \text { CI } 0.97-2.29)[10]\end{array}$ & $\mathrm{N}$ \\
\hline & \multirow[t]{3}{*}{$\begin{array}{l}\text { Truvada (Tenofovir } \\
\text { disoproxil fumarate \& } \\
\text { Emtricitabine) }\end{array}$} & $\begin{array}{l}N=1062 \\
\text { Hazard ratio } 0.94(95 \% \text { CI } 0.59-1.52 ; p=0.81)[9]\end{array}$ & $\mathrm{N}$ \\
\hline & & $N=985$ & \multirow[t]{2}{*}{$\mathrm{N}$} \\
\hline & & Hazard ratio 1.04 (95\% CI $0.73-1.49)$ [10] & \\
\hline
\end{tabular}


concern in Sub-Saharan Africa, South/Southeast Asia and the Latin America/Caribbean region [24, 26-29]; it is essential that PrEP does not drive drug resistance, further reducing treatment options for HIV-positive individuals.

The main practical limitation of event-driven PrEP is the complexity of the IPERGAY regime, which has led to concerns that adherence may be difficult. As such further evaluation in a variety of settings and risk groups is required. Furthermore, this regimen is not indicated in those with active hepatitis $B$ infection because of the risk of hepatic flares when the drug is interrupted.

Overall, the critical factors when deciding upon a PrEP regimen are adherence and the evidence base for the individual in question. Data support daily PrEP in MSM, heterosexual men and heterosexual women. However, data for event-based PrEP are limited to MSM only (one study only) and further data on tenofovir in women are desirable. It is likely that, as for HIV acquisition risk, PrEP requirements may differ for vaginal, penile and anal HIV acquisition prevention [30].

\section{CURRENT GUIDELINES AND PROGRAMMES}

Understanding the cultural context of PrEP provision is vital for implementation with factors such as sexual practice, age and gender playing important roles in HIV acquisition risk and acceptability of interventions. One model of PrEP provision therefore does not fit all communities or scenarios. For instance, the failure of the PrEP trials in women in Africa has been attributed to cultural and social factors including concerns of disclosure to male partners [9, 10]. Societal and personal factors affecting the acceptability and adherence to
PrEP are being explored in a variety of populations.

Since 2013 PrEP implementation has accelerated in the US where Truvada is licenced for use (FDA) [31] and has been used with this indication by more than 50,000 individuals [32], and PrEP has been included in the European AIDS Clinical Society (EACS) [33] and World Health Organisation (WHO) guidelines [34]. Pressure has increased globally for countries to submit to regulatory authorities and include PrEP in national policies.

Europe EACS guidelines advise tenofovir or Truvada daily as PrEP for heterosexuals at risk and Truvada daily or event-driven for MSM [35]. The European Centre for Disease Control revised their previous statement, which expressed concern about risk compensation, to recommend that "EU Member States should give consideration to integrating PrEP into their existing HIV prevention package for those most at-risk of HIV infection, starting with MSM." The European Medicines Agency has recently recommended a market authorisation for Truvada as PrEP in high-risk individuals (EMA [36]).

USA In the US, PrEP has been licenced for 4 years with numbers continuing to increase [32]. The CDC [37] has recommended daily Truvada-based PrEP for MSM, heterosexual men and women, and active injecting drug users who are at on-going risk of HIV acquisition, once HIV has been excluded. It also recommends that Tenofovir alone can be considered in non-MSM individuals, but event-based PrEP is not advocated.

Australia Truvada has been approved by Australia's Therapeutic Goods Administration for use as PrEP [38] but to date has not been agreed via the Pharmaceutical Benefits Scheme-and therefore can be obtained but only at full drug cost to the individual. 
Global The WHO recommends daily PrEP (Tenofovir and Truvada) for people at substantial risk of acquiring HIV infection but does not recommend event-driven PrEP [34].

\section{EFFECTIVENESS AND COST EFFECTIVENESS}

The key factor to determine the utility and priority of PrEP in a community or population is its effectiveness as an intervention. From a clinical and public health perspective the effectiveness could be considered as the number needing to access PrEP to prevent one new infection, and from the health economic and payer's viewpoint it would include the overall cost-effectiveness. Both effectiveness and cost-effectiveness depend on the efficacy and continued adherence to the intervention and on the risks/incidence rates of HIV acquisition in those not receiving PrEP. Cost effectiveness also includes the costs of the drug, monitoring and follow-up, as well as costs avoided by decreasing new infections. A further issue is analysis of how PrEP compares to different interventions (such as promotion of condom use, circumcision, antiretroviral treatment for those diagnosed HIV positive and frequent testing of high-risk HIV-negative individuals).

As a consequence of the high HIV incidence in the control/placebo groups in the PROUD and IPERGAY studies, and the large effect size in both trials, the number of MSM needed to treat to avert one infection in a year was very low (13 and 18 respectively). A preliminary cost-effectiveness evaluation using the eligibility criteria for these two trials and the $86 \%$ reduction in HIV incidence suggested that daily PrEP for MSM will be cost-effective if HIV testing continues at the current rate and there is no substantial change in the proportion of MSM who manage their risk with condoms [39]. The usage and cost of drug could be substantially reduced with an event-based regimen. The cost of drug will also reduce when tenofovir comes off patent (in Europe, the USA and Australia 2017/2018; emtricitabine no longer has a patent applied) provided a two-tablet regimen proves acceptable to potential subjects or a generic single tablet is marketed.

Modelling of individuals at high risk of HIV acquisition showed low incremental cost-effectiveness ratios (ICER) and costs per quality-adjusted life year (QALY) estimates $[40,41]$. PrEP has been calculated to be cost effective in high-risk MSM and heterosexual discordant couples [42, 43, 44, 46]. Furthermore, demonstration projects in MSM in the USA have shown that study effectiveness translates into real-life experience [45]. However although PrEP in such populations is highly clinically effective (with a stronger evidence base than behavioural interventions) it is costly in the short term with a high budget impact. Indeed the benefits for MSM in the UK may take $40+$ years to realise [46].

Modelling has shown that the most effective method of decreasing HIV incidence is through combination interventions. For intravenous drug users in the US, PrEP combined with frequent HIV testing as well as the commencement of ART for all those HIV positive was the most effective package at reducing incidence-however the costs were dramatically increased and cost-effectiveness decreased compared to single prevention strategies [47]. In Nigeria, the most effective intervention was modelled to be a combination of treatment of HIV-positive partners and condom promotion rather than PrEP [48]. Similar modelling in Zambia and South Africa 
confirmed the larger impact of treatment of positive individuals at earlier stages of disease over PrEP [49]. Therefore, with limited resources, PrEP may not be the primary intervention chosen in some settings.

If other prevention methodologies, such as increased diagnosing of the undiagnosed and offering efficacious anti-retrovirals to all those known positive (pursuing the UNAIDS 90-90-90 programme), are improved then PrEP may have a decreased potential impact and role [50]. A separate consideration is that highly targeted strategies, focussing on the most cost-effective groups only, may not have large population-level impacts [51]. It is therefore important for a country to determine the preferred outcomes and direct interventions accordingly.

\section{CONCLUSIONS}

PrEP can be a highly effective HIV prevention strategy to be added to the toolbox of HIV prevention. Establishing a place for this tool in HIV prevention in specific populations is highly influenced by drug cost, user acceptability and political will. Together with treatment as prevention and other interventions, PrEP provides a significant opportunity to reduce HIV incidence significantly and should be a high priority for consideration by health systems and funders.

\section{ACKNOWLEDGMENTS}

No funding or sponsorship was received for this study or publication of this article.

All named authors meet the International Committee of Medical Journal Editors (ICMJE) criteria for authorship for this manuscript, take responsibility for the integrity of the work as a whole and have given final approval for the version to be published.

Disclosures. Dr Olubanke Davies has no conflicts of interest. Dr Andrew Ustianowski has received speaker fees and advisory board fees from Gilead, ViiV, Abbvie, MSD, Janssen and BMS. Dr Julie Fox has received research grants from Gilead, Viiv Healthcare and MSD.

Compliance with Ethics Guidelines. This article is based on previously conducted studies and does not involve any new studies of human or animal subjects performed by any of the authors.

Open Access. This article is distributed under the terms of the Creative Commons Attribution-NonCommercial 4.0 International License (http://creativecommons.org/licenses/ by-nc/4.0/), which permits any noncommercial use, distribution, and reproduction in any medium, provided you give appropriate credit to the original author(s) and the source, provide a link to the Creative Commons license, and indicate if changes were made.

\section{REFERENCES}

1. Baeten JM, Donnell D, Ndase P, Mugo NR, Campbell JD, Wangisi J, et al. Antiretroviral prophylaxis for HIV prevention in heterosexual men and women. $\mathrm{N}$ Engl J Med. 2012;367(5):399-410.

2. Choopanya K, Martin M, Suntharasamai $P$, Sangkum U, Mock PA, Leethochawalit M, et al. Antiretroviral prophylaxis for HIV infection in injecting drug users in Bangkok, Thailand (the Bangkok Tenofovir Study): a randomised, double-blind, placebo-controlled phase 3 trial. Lancet. 2013;381(9883):2083-90.

3. McCormack S, Dunn DT, Desai $M$, et al. Pre-exposure prophylaxis to prevent the acquisition of HIV-1 infection (PROUD): effectiveness results from the pilot phase of a 
pragmatic open-label randomised trial. Lancet. 2016;387(10013):53-60.

4. Grant RM, Lama JR, Anderson PL, McMahan V, Liu AY, Vargas L, et al. Preexposure chemoprophylaxis for HIV prevention in men who have sex with men. N Engl J Med. 2010;363(27):2587-99.

5. Thigpen MC, Kebaabetswe PM, Paxton LA, Smith DK, Rose CE, Segolodi TM, et al. Antiretroviral preexposure prophylaxis for heterosexual HIV transmission in Botswana. $\mathrm{N}$ Engl $\mathrm{J}$ Med. 2012;367(5):423-34.

6. Molina JM, Capitant C, Spire B, et al. On-demand preexposure prophylaxis in men at high risk for HIV-1 infection. N Engl J Med. 2015;373:2237-46.

7. Karim QA, Karim SSA, Frohlich JA, Grobler AC, Baxter C, Mansoor LE, et al. Effectiveness and safety of tenofovir gel, an antiretroviral microbicide, for the prevention of HIV infection in women. Science. 2010;329(5996):1168-74.

8. Rees H, Delany-Moretlwe S, Baron D, Lombard C, Gray G, Myer L, et al., editors. FACTS 001 phase III trial of pericoital tenofovir $1 \%$ gel for HIV prevention in women. Conference on Retroviruses and Opportunistic Infections (CROI); 2015.

9. Van Damme L, Corneli A, Ahmed K, et al. Preexposure prophylaxis for HIV infection among African women. N Engl J Med. 2012;367:411-22.

10. Marrazzo JM, Ramjee G, Richardson BA, et al. Tenofovir-based preexposure prophylaxis for HIV infection among African women. N Engl J Med. 2015;372:509-18.

11. Grant RM, Anderson PL, McMahan V, et al. Uptake of pre-exposure prophylaxis, sexual practices, and HIV incidence in men and transgender women who have sex with men: a cohort study. Lancet Infect Dis. $2014 ; 14(9): 820-9$.

12. Kasonde M, Niska RW, Rose C. Bone mineral density changes among HIV-uninfected young adults in a randomised trial of pre-exposure prophylaxis with tenofovir-emtricitabine or placebo in Botswana. PLoS One. 2014;9(3):e90111.

13. Mulligan K, Glidden DV, Anderson PL, et al. Effects of emtricitabine/tenofovir on bone mineral density in HIV-negative persons in a randomized, double-blind, placebo-controlled trial: DXA results from iPrEx. Clin Infect Dis. 2015;61(4):572-80.

14. Solomon MM, Lama JR, Glidden DV, et al. Changes in renal function associated with oral emtricitabine/tenofovir disoproxil fumarate use for HIV pre-exposure prophylaxis. AIDS. 2014;28(6):851-9.
15. Massud I, Mitchell J, Babusis D, Garcia-Lerma G, et al. Chemoprophylaxis with Oral FTC/TAF protects macaques from rectal SHIV infection. Conference on retroviruses and opportunistic infections. Boston, February 22-25, 2016. Abstract 107.

16. Garrett KL, Cottrell ML, Prince HMA. Concentrations of TFV and TFVdp in female mucosal tissues after a single dose of TAF. Conference on retroviruses and opportunistic infections (CROI). February 22-25, 2016, Boston.

17. Ford N, et al. Comparative efficacy of lamivudine and emtricitabine: a systematic review and meta-analysis of randomized trials. PLoS One. 2013;8(11):e79981. doi:10.1371/journal.pone. 0079981.

18. Fox J, Herrera C, Tiraboschi JM et al. Pharmacokinetic/pharmacodynamic investigation of single dose oral maraviroc in the context of HIV-1 pre exposure prophylaxis. JAIDS. 2016 (Epub ahead of print).

19. McGowan I for the HPTN 069/ACTG 5305 Team PrEP impact on T-cell activation and explant infection: HPTN 069/ACTG 5305 study. Conference on Retroviruses and Opportunistic Infections (CROI 2016), Boston. Oral presentation\#104. 2016.

20. Gulick R, et al. HPTN 069/ACTG A5305: phase II study of maraviroc-containing regimens for HIV PrEP in United States (U.S.) women. AIDS 2016, Durban. Oral abstract TUAC0102.

21. Gulick R, Wilkin TJ, Chen Y, et al. HPTN 069/ACTG 5305: phase II study of maraviroc-based regimens for HIV PrEP in MSM. Conference on retroviruses and opportunistic infections (CROI), February 22-25, 2016, Boston. Abstract 103. http://www. how2offerprep.org/.

22. Markowitz $M$ et al. ÉCLAIR: phase 2 a safety and PK study of cabotegravir LA in HIV-infected men. Conference on retroviruses and opportunistic infections, Boston, 2016. Abstract 106.

23. Baeten JM, Palanee-Phillips T, Brown ER et al. Use of a vaginal ring containing dapivirine for HIV-1 prevention in women. Published online February 22, 2016. doi:10.1056/NEJMoa1506110.

24. Frentz D, Boucher CA, van de Vijver DA. Temporal changes in the epidemiology of transmission of drug-resistant HIV-1 across the world. AIDS Rev. 2012;14:17-27.

25. Grant R. Complications from head to toe. Presentation at conference on retroviruses and opportunistic infections, Feb 22-25, 2016. Seattle. 
26. World Health Organization. WHO HIV Drug resistance report 2012. Available from: http:// www.who.int/hiv/pub/drugresistance/report2012/ en/. Accessed 26 Jun 2016.

27. Gupta RK, Wainberg MA, Brun-Vezinet F, et al. Oral antiretroviral drugs as public health tools for HIV prevention: global implications for adherence, drug resistance, and the success of HIV treatment programs. J Infect Dis. 2013;207(Suppl 2):S101-6.

28. Hamers RL, Oyomopito R, Kityo C, et al. The PharmAccess African (PASER-M) and the TREAT Asia (TASER-M) monitoring studies to evaluate resistance-HIV drug resistance in sub-Saharan Africa and the Asia-Pacific 21 April 2011. Int J Epidemiol. 2012;41(1):43-54.

29. Hamers RL, Wallis CL, Kityo C, et al. HIV-1 drug resistance in antiretroviral-naive individuals in sub-Saharan Africa after rollout of antiretroviral therapy: a multicentre observational study. Lancet Infect Dis. 2011;11:750-9.

30. Patterson KB, Prince HA, Kraft E, Jenkins AJ, Shaheen NJ, Rooney JF, Cohen MS, Kashuba AD. Penetration of tenofovir and emtricitabine in mucosal tissues: implications for prevention of HIV-1 transmission. Sci Transl Med. 2011;3(112):112re4.

31. US Food and Drug Administration. FDA approves first drug for reducing the risk of sexually acquired HIV infection. Available from: http://www.fda.gov/ NewsEvents/Newsroom/PressAnnouncements/ucm 312210.htm. Accessed 26 Jun 2016.

32. Mera RM, Rawlings MK, Pechonkina A, Rooney JF, Peschel T, Cheng A. Status of Truvada (TVD) for HIV pre-exposure prophylaxis (PrEP) in the United States: an early drug utilization analysis. Paper presented at: 53rd ICAAC interscience conference on antimicrobial agents and chemotherapy, September 10-13, 2013, Denver.

33. European AIDS Clinical Society guidelines. 2015; Version 8: Available from: http://www.eacsociety. org/guidelines/eacs-guidelines/eacs-guidelines.html. Accessed 26 Jun 2016.

34. World Health Organisation. Guideline on when to start antiretroviral therapy and on pre-exposure prophylaxis for HIV. 2015. Available from: http:// www.who.int/hiv/pub/guidelines/earlyrelease-arv/ en/. Accessed 26 June 2016.

35. European Centre for Disease Control. HIV and STI prevention among men who have sex with men. http://ecdc.europa.eu/en/publications/publications/ hiv-sti-prevention-among-men-who-have-sex-withmen-guidance.pdf. Accessed 26 June 2016.
36. European Medicines Agency. First medicine for HIV pre-exposure prophylaxis recommended for approval in the EU. http://www.ema.europa.eu/ ema/index.jsp?curl=pages/news_and_events/news/ 2016/07/news_detail_002578.jsp\&mid=WC0b01ac 058004d5c1. Accessed 16 Aug 2016.

37. Centers for disease control and prevention. US Public Health Service Preexposure prophylaxis for the prevention of HIV infection in the United States-2014. A clinical practice guideline. http://www.cdc.gov/hiv/pdf/prepguidelines2014. pdf. Accessed 26 Jun 2016.

38. Australia's Therapeutic Goods Administration. Prescription medicines: new or extended uses, or new combinations of registered medicines. https:// www.tga.gov.au/prescription-medicines-new-orextended-uses-registered-medicines. Accessed 26 Jun 2016.

39. Cambiano VMA, Dunn D, McCormack S, Ong K, Gill N, Nardone A, Desai M, Rodger A, Phillips A. Is pre-exposure prophylaxis for HIV prevention cost-effective in men who have sex with men in the UK? BASHH Spring Conference; Glasgow 2015.

40. Fonner VA, Dalglish SL, Kennedy CE, et al. Effectiveness and safety of oral HIV pre-exposure prophylaxis (PrEP) for all populations: a systematic review and meta-analysis. AIDS. 2016;30(12):1973-83.

41. Ross EL, Cinti SK, Hutton DW. Implementation and operational research: a cost-effective, clinically actionable strategy for targeting HIV pre-exposure prophylaxis to high-risk men who have sex with men. J Acquir Immune Defic Syndr. 2016;72(3):e61-7.

42. Ying R, Heffron R, Celum C, Baeten JM, Katabira E, Bulya $\mathrm{N}$, et al. Cost-effectiveness of pre-exposure prophylaxis targeted to high-risk serodiscordant couples as a bridge to sustained ART use in Kampala, Uganda. J Int AIDS Soc. 2015;18:20013.

43. Cambiano V, Miners A, Phillips A. What do we know about the cost-effectiveness of HIV preexposure prophylaxis, and is it affordable? Curr Opin HIV AIDS. 2016;11(1):56-66.

44. Juusola JL, Brandeau ML, Owens DK, Bendavid E. The cost-effectiveness of PrEP in the United States in MSM. Ann Intern Med. 2012;156(8):541-50.

45. Liu AY, Cohen SE, Vittinghoff E, Anderson PL, Doblecki-Lewis S, Bacon O, Chege W, Postle BS, Matheson T, Amico KR, Liegler T, Rawlings MK, Trainor N, Blue RW, Estrada $\mathrm{Y}$, Coleman ME, Cardenas G, Feaster DJ, Grant R, Philip SS, Elion R, Buchbinder S, Kolber MA. Preexposure 
prophylaxis for HIV infection integrated with municipal- and community-based sexual health services. JAMA Intern Med. 2016;176(1):75-84.

46. Cambiano V. Cost-effectiveness of ART as prevention Unpublished conference presentation at British HIV Association annual conference, April 20, 2016. Manchester.

47. Bernard CL, Brandeau ML, Humphreys K, et al. Cost-effectiveness of HIV preexposure prophylaxis for people who inject drugs in the United States. Ann Intern Med. 2016. doi:10.7326/M15-2634 (Epub ahead of print).

48. Mitchell KM, Lépine A, Terris-Prestholt F, et al. Modelling the impact and cost-effectiveness of combination prevention amongst HIV serodiscordant couples in Nigeria. AIDS. 2015;29(15):2035-44.

49. Nichols BE, Baltussen R, van Dijk JH, et al. Cost-effectiveness of PrEP in HIV/AIDS control in Zambia: a stochastic league approach. J Acquir Immune Defic Syndr. 2014;66:221-8.

50. UNAIDS 90-90-90. An ambitious treatment target to help end the AIDS epidemic. http://www.unaids. org/sites/default/files/media_asset/90-90-90_en_0. pdf. Accessed 16 Aug 2016.

51. Schneider K, Gray RT. Wilson DP a cost-effectiveness analysis of HIV preexposure prophylaxis for men who have sex with men in Australia. Clin Infect Dis. 2014;58(7):1027-34. doi:10.1093/cid/cit946. 